\title{
Patients' Preferences for Ways to Communi- cate Benefits of Cardiovascular Medication
}

\author{
Felicity Goodyear-Smith, MB CbB, \\ MGP \\ Timothy Kenealy, $\mathrm{MB} C \mathrm{CbB}, \mathrm{PbD}$ \\ Susan Wells, MB CbB, PbD \\ Bruce Arroll, $M B C b B, P b D$ \\ Margaret Horsburgh, MA, EdD \\ University of Auckland, Auckland, \\ New Zealand

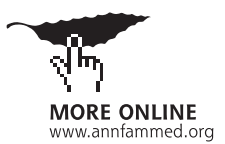

Conflicts of interest: none reported.

\section{CORRESPONDING AUTHOR}

Felicity Goodyear-Smith, MB CHB, MGP Department of General Practice and Primary Health Care

University of Auckland

Private Bag 92019

Auckland 1142 New Zealand

f.goodyear-smith@auckland.ac.nz

\begin{abstract}
PURPOSE We wanted to determine patients' willingness to take preventive cardiovascular disease (CVD) medication in relation to their 5-year CVD risk score and modes of communicating benefits of therapy.

METHODS Study participants were 934 consecutive patients drawn from family practitioners' waiting rooms in Auckland, New Zealand, who knew their 5-year CVD risk (ranging from $5 \%$ to $30 \%$ ) and who completed a questionnaire asking them to rate how much various modes of communicating the benefits of therapy would encourage them to take medication daily, where the benefits from medication were proportional to their estimated CVD risk score.
\end{abstract}

RESULTS Patients' rankings for modes of communicating the benefits of therapy were little influenced by sex, age, ethnicity, numeracy score, 5-year CVD risk, or concern about a heart attack. Patients clearly found relative risk reduction most encouraging, with absolute risk reduction rated second overall and numbers needed to treat the least likely to be persuasive, although preferences covered the full range and were not predictable from demographic or 5-year CVD risk data. Pictures were preferred to numbers by $55.1 \%$, with a people-chart or a bar chart being equally favored. Even so, $61.8 \%$ preferred a doctor's opinion to any presentation by numbers or pictures.

CONCLUSIONS Patients' willingness to take preventive cardiovascular medication depends more on mode of communicating treatment benefit than on their shortterm CVD risk score or their level of concern about a future cardiovascular event. Because individual preferences were not predictable, more than 1 modality is likely to be clinically useful for each patient.

Ann Fam Med 2011;9:121-127. doi:10.1370/afm.1193.

\section{INTRODUCTION}

$\mathrm{P}$ rimary health clinicians use population-based data on the probability of cardiovascular disease (CVD) as a basis for offering interventions to individual patients. In New Zealand, the calculations include adjustments for ethnicity, high-risk diabetes subgroups, and family history. ${ }^{1}$ For individual patients, the related decisions can be complex and often accompanied by uncertainty when applying population data to themselves. There is scarce evidence that the relevant information is effectively communicated to patients. ${ }^{2}$

Complicating this issue is that patient decision making is not fully rational ${ }^{3}$; patients do not make uniform and predictable decisions based on the same information or on the same information presented in differing ways. ${ }^{4}$ The information can result in patients drawing completely different conclusions. ${ }^{5,6}$ Patients express a strong preference for some modes of communicating treatment benefits over others-preferring pictures to words ${ }^{4}$ and relative risk reduction to other numerical presentations. ${ }^{7}$ In all these respects, patients do not differ from clinicians. ${ }^{8}$ By their choice of words or pictures, however, physicians and drug companies alike can influ- 
ence their patients' decision making, which can potentially have a serious impact on health care outcomes. ${ }^{9}$

Physicians are likely to be highly inaccurate when quantifying their own or their patients' CVD risk without a calculator or decision aid. ${ }^{10,11}$ A systematic review of individualized risk communication based on the individual's own risk factors or risk for a condition has been associated with increased uptake of screening tests. ${ }^{12}$ In terms of motivation to take preventive drugs, previous studies of communicating benefits for CVD prevention have included only high-risk patients (who are often highly motivated to take medication regardless of mode of risk communication $)^{4}$ or patients who do not know their own short-term CVD risk score. ${ }^{7}$ With this study, we sought to extend this previous work to include a wide range of modes of communicating treatment benefits across patients with a wide range of CVD risk (including primary and secondary prevention), where the scenario is made realistic by adapting the questions and treatment benefits to the CVD risk score of each respondent. For these patients, we wanted to determine their willingness to take CVD medication in relation to their 5-year CVD risk score and the modes of communicating benefits of therapy.

\section{METHODS}

\section{Setting}

We drew the study sample from patients attending 9 Auckland family medicine practices in 2007 to 2009. Patients were chosen from low-, middle-, and highsocioeconomic areas, including 2 practices with a high proportion of Māori and Pacific Islanders. New Zealand guidelines recommend cardiovascular screening for Māori and Pacific Islanders 10 years earlier than recommended for other populations, and for men 10 years earlier than women, because of the higher burden of heart disease at a younger age for Mãori, Pacific Islanders, and men. ${ }^{1}$ Several practices were running a CVD screening program at the time of the study, increasing the number of men available for the study. At that time, all patients would have paid NZ\$3 for 3 months of subsidized cardiovascular medications.

\section{Participants}

A research assistant in the waiting room invited consecutive patients to participate and obtained written consent. Patients completed a version of the questionnaire most appropriate to their 5-year CVD risk. Where their disease risk had already been established, the percentage risk was provided from their electronic health records with the patient's consent; otherwise, it was estimated by the research assistant using a Framingham-based risk calculation color chart using the patients' age, sex, ethnicity, smoking status, and history of hypertension, diabetes, or a CVD event. Participants could complete the questionnaire during a faceto-face interview, they could complete it later by telephone with the research assistant, or they could return it by mail using a prepaid envelope. We excluded patients who were younger than 30 years, were unable to speak English, had dementia, were intoxicated with alcohol, or had taken part in our previous study. ${ }^{4}$

\section{Questionnaire}

The questionnaire used in our previous study was adapted for a new audience and pilot tested by the investigators. Questionnaires were tailored to a 5-year CVD risk of $5 \%, 10 \%, 15 \%, 20 \%, 25 \%$, and $30 \%$ (the $15 \%$ version is shown in the Supplemental Appendix, available online at http://annfammed.org/cgi/ content/full/9/2/121/DC1. The overall instructions to patients stated that they were being asked to consider a new medication with few side-effects to be taken daily to reduce their chance of having a heart attack in the next 5 years. We chose heart attack and did not include stroke because the estimated risk reduction used in the questionnaire was based on a meta-analysis of lipid-lowering drug use for primary prevention of coronary heart disease. ${ }^{13}$ Although questions specified their risk of heart attack, it is strongly correlated with their 5-year CVD risk. ${ }^{14}$

The questionnaire included 5 numerical modes of communicating treatment benefits: relative risk, absolute risk, odds, number needed to treat, and natural frequencies. The same information was presented in 2 pictorial forms (bar graphs and $10 \times 10$ people charts). Patients ranked the numerical modes of risk communication in order of those that "would encourage you to take this medication every day," and in order of which "statement helps you make a decision." Questions also addressed patients' preference for the type of pictorial representation, numbers vs pictures, and framing that is positive ( $99 \%$ success) or negative (1\% failure).

We assumed a causal sequence of perceptions and attitudes in which real cardiovascular risk leads to perceived likelihood of myocardial infarction, which leads to concern about a myocardial infarction, which leads to keenness to take medication. Patients rated their perceived likelihood of having a heart attack in the next 5 years on a scale from 1 (not likely) to 10 (very likely), their concern about having a heart attack on a scale from 1 (not concerned at all) to 10 (extremely concerned), and how they felt about taking daily preventative medication on a scale from 1 (not keen at all) to 10 (keen to take medication).

We collected data on sex, age, ethnicity, and educational level. Patients were assigned a numeracy 
score between 0 and 3 based on their understanding of probability, percentages, and proportions using the numeracy test developed by Schwartz et al. ${ }^{15}$ Social deprivation quintile was calculated from the patients' residential address and NZDep (index of deprivation)

\section{Table 1. Description of Participants ( $N=934)$}

\begin{tabular}{|c|c|c|}
\hline Variable & $\mathbf{n}$ & $\%$ \\
\hline \multicolumn{3}{|l|}{ Sex } \\
\hline Male & 477 & 51.1 \\
\hline Female & 457 & 48.9 \\
\hline \multicolumn{3}{|l|}{ Ethnicity } \\
\hline European/other & 693 & 74.2 \\
\hline Māori & 72 & 7.7 \\
\hline Pacific Islander & 55 & 5.9 \\
\hline Asian & 114 & 12.2 \\
\hline \multicolumn{3}{|l|}{ Age range, $y$} \\
\hline $31-40$ & 44 & 4.7 \\
\hline $41-50$ & 199 & 21.3 \\
\hline $51-60$ & 273 & 29.2 \\
\hline $61-70$ & 237 & 25.4 \\
\hline$>70$ & 181 & 19.4 \\
\hline \multicolumn{3}{|l|}{ Highest education } \\
\hline Primary & 42 & 4.5 \\
\hline Secondary & 464 & 49.7 \\
\hline Technical & 188 & 20.1 \\
\hline University & 240 & 25.7 \\
\hline \multicolumn{3}{|l|}{ Numeracy score } \\
\hline 0 & 85 & 9.1 \\
\hline 1 & 201 & 21.5 \\
\hline 2 & 306 & 32.8 \\
\hline 3 & 342 & 36.6 \\
\hline \multicolumn{3}{|c|}{ Social deprivation of domicile } \\
\hline 1 (least deprived) & 249 & 26.7 \\
\hline 2 & 214 & 22.9 \\
\hline 3 & 166 & 17.8 \\
\hline 4 & 110 & 11.8 \\
\hline 5 (most deprived) & 166 & 17.8 \\
\hline Missing & 29 & 3.1 \\
\hline
\end{tabular}

scores. ${ }^{16}$ We also asked patients whether they followed horse racing to test a hypothesis that their interest might correlate with a preference for risk expression using odds.

\section{Analysis}

We used Stata 10.1 (StataCorp LP, College Station, Texas) to analyze the data. We used $\chi^{2}$ to compare simple proportions, linear regressions to examine associations of continuous or ordinal variables (such as CVD risk), logistic regressions to examine associations of binary variables (such as preference for pictures over numbers), and multinomial logistic regression to examine associations with a series of related binary variables (in this case a first-ranked preference for relative risk compared with a first-ranked preference for each of the other numerical modes of expressing risk); we cite statistical significance at $P \leq .05$. All regressions are adjusted for clustering by the family practice from which participants were recruited.

\section{Ethical Approval}

The Northern X Regional Ethics Committee approved this study (Reference NTX/06/09/108).

\section{RESULTS}

The sample consisted of 934 participants (Table 1) from 9 practices, of whom $19 \%$ were at low CVD risk $(<10 \% 5$-year CVD risk), $35 \%$ were at moderate risk (10\%-14\% 5-year CVD risk), and the remaining 46\% were at high or very high risk (15\% 5-year CVD risk or higher). Data were collected face to face from 689 participants and by telephone (95), mail (98), or mixed methods (52).

Participants' preferences for modes of numeric communication are summarized in Table 2 and Figure 1 , and other responses are summarized in Table 3.

Most patients $(61.8 \%$, Table 3$)$ pre-

Table 2. Participant's Rankings for Numerical Explanatory Modes That Would Encourage Them to Take Medication and Help Them to Make a Decision ( $\mathrm{N}=934)$

\begin{tabular}{|c|c|c|c|c|}
\hline \multirow[b]{2}{*}{ Mode } & \multicolumn{2}{|c|}{$\begin{array}{l}\text { Would Encourage to } \\
\text { Take Medication }\end{array}$} & \multicolumn{2}{|c|}{$\begin{array}{l}\text { Would Help to } \\
\text { Make a Decision }\end{array}$} \\
\hline & $\begin{array}{c}\text { Ranked 1st } \\
\text { n (\%) }\end{array}$ & $\begin{array}{c}\text { Reversed } \\
\text { Rank Sum }\end{array}$ & $\begin{array}{c}\text { Ranked 1st } \\
\text { n (\%) }\end{array}$ & $\begin{array}{c}\text { Reversed } \\
\text { Rank Sum }\end{array}$ \\
\hline Relative risk reduction & $605(64.8)$ & 4,042 & $603(64.5)$ & 3,988 \\
\hline Absolute risk & 107 (11.5) & 3,040 & $131(14.0)$ & 3,149 \\
\hline Natural frequencies & $103(11.0)$ & 2,080 & $91(9.7)$ & 1,989 \\
\hline Odds & $85(9.1)$ & 2,706 & $76(8.1)$ & 2,668 \\
\hline $\begin{array}{l}\text { Number needed } \\
\text { to treat }\end{array}$ & $32(3.4)$ & 2,136 & $32(3.4)$ & 2,213 \\
\hline
\end{tabular}

ferred a doctor to give an opinion than to explain using either numbers or pictures, and more than onehalf (55.2\%) preferred pictures to numbers. There was no significant difference between men and women, or between ethnic groups, for those who preferred pictures to numbers. There was no significant difference in preference for odds being presented between those who bet on horses and those who did not. Logistic regression suggests that pictures are preferred over numbers, independently, by those with less 
schooling $(\mathrm{OR}=1.2 ; \mathrm{CI}, 1.1-1.3)$ and by those who were less numerate $(\mathrm{OR}=1.1 ; \mathrm{CI}, 1.01-1.2)$.

We used a series of regressions to examine our assumed sequence of perceptions and attitudes in decision making. Short-term CVD risk explained only $7.4 \%$ of the variance of perceived likelihood of having a heart attack. Perceived likelihood explained

only $6.3 \%$ of variance in concern. Concern explained only $1.4 \%$ of variance in keenness to take medication. Keenness to take medication was not associated with ethnicity, age, sex, numeracy level, social deprivation score, concern about having a heart attack, preference for numbers or pictures, explanation or opinion, or first ranking of absolute risk reduction, natural frequencies, odds, or number needed to treat.

Keenness to take medication Figure 1. Ranks assigned to modes of risk communication (from $1=$ most to 5 = least).

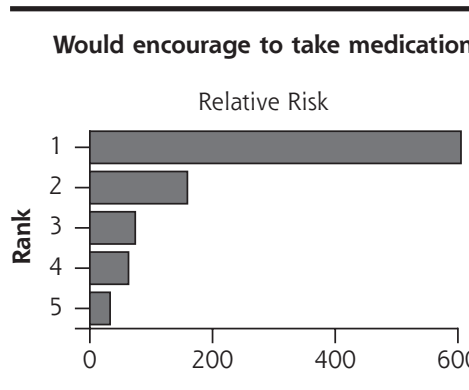

Would help to make a decision
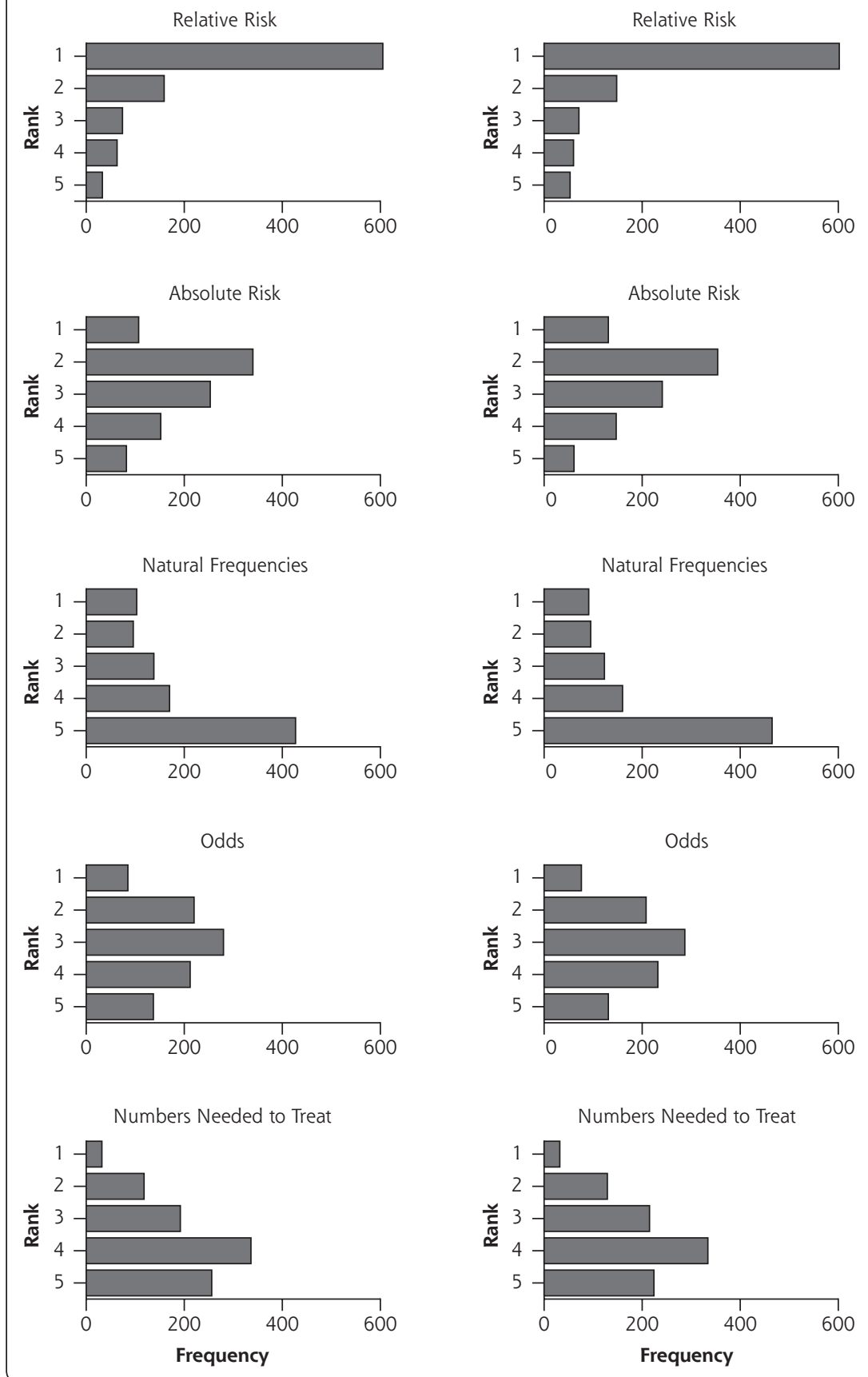
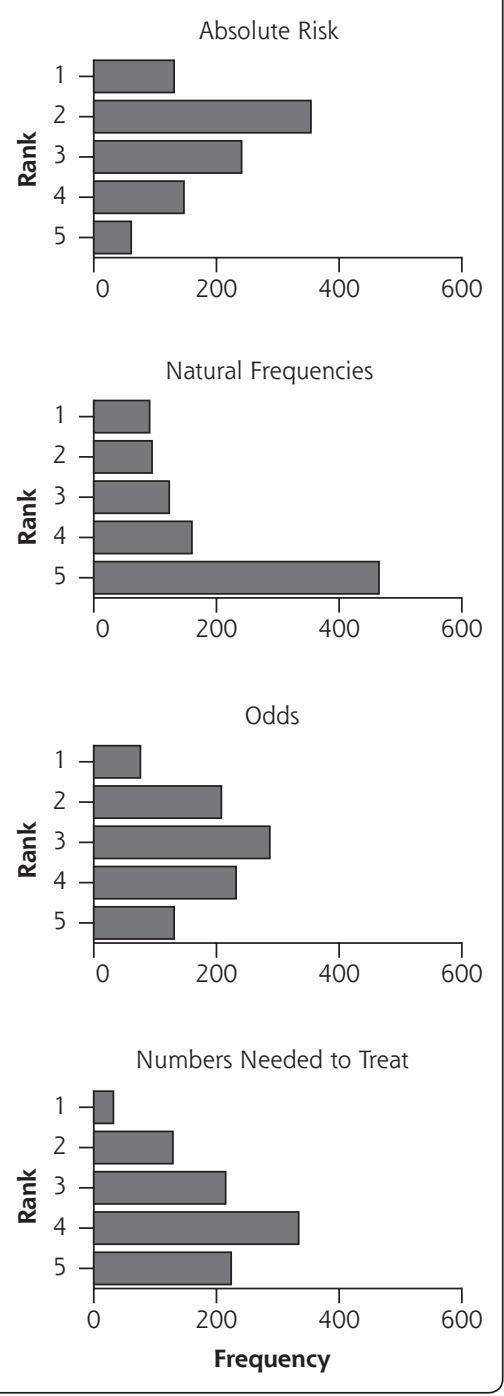
was positively associated with older age, higher CVD risk, perceived likelihood of having a heart attack, and having had only primary school education (Table 4). Perceived likelihood of having a heart attack was positively associated with increasing CVD risk, concern about having a heart attack, being Mãori, and it was negatively associated with being more numerate and more educated.

We examined the odds of relative risk being ranked first as encouraging participants to take medication in relationship to a series of predictor variables using logistic regression. Relative risk was ranked first by more numerate people $(\mathrm{OR}=1.2 ; 95 \% \mathrm{CI}$, 1.0-1.4), those who were more concerned about a heart attack $(\mathrm{OR}=1.1 ; 95 \% \mathrm{CI}, 1.01-1.2)$, and less by Pacific Islander $(\mathrm{OR}=0.4)$ and Asian $(\mathrm{OR}=0.4)$ participants (ethnicity overall, 95\% CI, 0.7$0.8)$. No significant relationships were found for age, sex, education, social deprivation, keenness to take medication, perceived likelihood to have a heart attack, calculated cardiovascular risk, preference for pictures or numbers, positive or negative framing, or preference for explanation or opinion from the doctor. This regression explained only $3 \%$ of the variance in the data.

Comparing the group that ranked relative risk first with the group that ranked other modes as most likely to encourage them to take medication results in the pattern displayed in Table 5. 
Table 3. Participant Responses to Other Questionnaire Items ( $\mathbf{N}=934)$

\begin{tabular}{lc}
\hline Item & Mean (SD) \\
\hline Concern about a heart attack & $4.1(2.5)$ \\
Perceived likelihood of a heart attack & $3.7(2.4)$ \\
Keenness to take medication & $7.0(3.3)$ \\
& $\mathbf{n}(\%)$ \\
\cline { 2 - 2 } Prefer pictures to numbers & $516(55.2)$ \\
Prefer people chart to bar graph & $468(50.1)$ \\
Prefer positively framed to negatively & $650(69.6)$ \\
framed statement & $211(22.6)$ \\
No preference & $577(61.8)$ \\
Prefer doctor to give opinion rather than & \\
$\quad$ explain using numbers and/or pictures & $12(1.3)$ \\
No preference & \\
\hline a Scored on a 10-point scale in which 1 = least concern/perceived likelihood/ \\
keenness, and 10 = most concerned/perceived likelihood/keenness.
\end{tabular}

\section{Table 4. Linear Regressions of Associations With Keenness to Take Medication and With Perceived Likelihood of Having Heart Attack}

\begin{tabular}{lcc}
\hline Association & Coefficient & $\begin{array}{c}P \\
\text { Value }\end{array}$ \\
\hline $\begin{array}{l}\text { Associations with keenness to take } \\
\text { medication }\end{array}$ & & \\
Calculated cardiovascular disease risk & 0.38 & .01 \\
Perceived likelihood of heart attack & 0.35 & $<.001$ \\
Primary school education only & 1.38 & .02 \\
Older age & 0.31 & .02 \\
Associations with perceived likelihood & & \\
of having a heart attack & & \\
Calculated cardiovascular disease risk & 0.40 & $<.001$ \\
Numeracy & -0.28 & .002 \\
Education level & -0.25 & $<.001$ \\
Māori & 1.13 & 0.002 \\
Concern about heart attack & 0.22 & 0.001 \\
\hline${ }^{\mathrm{a}} \mathrm{n}=928 ; R^{2}=0.16$. & & \\
${ }^{\mathrm{b}} \mathrm{n}=927 ; R^{2}=0.17$ & & \\
\hline
\end{tabular}

Those who ranked absolute risk first were more likely to be Asian; those favoring natural frequencies were more likely to have lower literacy, follow horse racing, prefer pictures to numbers, and be Pacific Islander or Asian, and those favoring odds or number needed to treat were likely to follow horse racing and less likely to be concerned about a heart attack. This regression explained only $4.8 \%$ of variance in the data.

\section{DISCUSSION}

\section{Summary of Main Findings}

More than $60 \%$ of participants preferred a doctor to give them an opinion on medication rather than explain the risks; slightly more than one-half preferred
Table 5. Comparing Groups by First-Ranked Responses For Mode of Risk Communication That Would Most Encourage Them to Take Medication

\begin{tabular}{|c|c|c|}
\hline $\begin{array}{l}\text { Explanatory Mode } \\
\text { Compared With RRR }\end{array}$ & Coefficient & $P$ Value \\
\hline \multicolumn{3}{|l|}{ Absolute risk reduction } \\
\hline Numeracy & -0.11 & .14 \\
\hline Follows horse racing & 0.02 & .96 \\
\hline Prefer pictures to numbers & -0.14 & .27 \\
\hline Concern about heart attack & -0.04 & .34 \\
\hline Pacific Islander & 0.10 & .58 \\
\hline Asian & 0.66 & .003 \\
\hline \multicolumn{3}{|l|}{ Natural frequencies } \\
\hline Numeracy & -0.34 & .002 \\
\hline Follows horse racing & 0.89 & $<.001$ \\
\hline Prefer pictures to numbers & 0.60 & .02 \\
\hline Concern about heart attack & -0.07 & .23 \\
\hline Pacific Islander & 1.55 & $<.001$ \\
\hline Asian & 1.44 & $<.001$ \\
\hline \multicolumn{3}{|l|}{ Odds } \\
\hline Numeracy & -0.07 & .40 \\
\hline Follows horse racing & 0.53 & $<.001$ \\
\hline Prefer pictures to numbers & -0.39 & .09 \\
\hline Concern about heart attack & -0.15 & $<.001$ \\
\hline Pacific Islander & 0.33 & .38 \\
\hline Asian & -0.04 & .77 \\
\hline \multicolumn{3}{|l|}{ Number needed to treat } \\
\hline Numeracy & -0.05 & .64 \\
\hline Follows horse racing & 0.91 & $<.001$ \\
\hline Prefer pictures to numbers & -0.27 & .12 \\
\hline Concern about heart attack & -0.14 & .05 \\
\hline Pacific Islander & 0.47 & .38 \\
\hline Asian & 0.75 & .18 \\
\hline
\end{tabular}

$\mathrm{RRR}=$ relative risk reduction.

Note: Multinomial logistic regression with first preference for relative risk taken as the reference group $\left(\mathrm{n}=880\right.$, pseudo $\left.R^{2}=0.05\right)$.

a pictorial presentation to numbers; and of the numerical presentations, nearly two-thirds preferred relative risk to other ways of presenting the same data. They did not distinguish between the mode of explanation that would encourage them to take medication and the mode they found most helpful to make a decision. Statistically significant associations were found between various preferences, attitudes, and patient descriptors, but our overall impression was that these associations explained only a small portion of the variance in the data, and the patterns were not sufficiently distinctive to be useful to clinicians in deciding how to communicate with an individual patient.

\section{Strengths and Limitations of This Study}

Strengths of this study include having consecutive patients; a wide range of age, ethnicity, and risk ${ }_{i}$ and tailoring the questionnaires to the patients' 5 -year 
CVD risk. Our sample had more men than might be expected from a routine family practice clinic, which we attribute to the planned cardiovascular screening in several clinics, where men were invited as a priority and at a younger age because of their increased cardiovascular risk compared with women.

The options were always presented in the same order in the questionnaire: relative risk, absolute risk, number needed to treat, odds, and natural frequencies. There may have been some selection bias resulting from the order sequence, although the results indicate that this would only have been a minor effect. Nevertheless, to prevent such a possible bias, subsequent studies should present each option in random order.

\section{Comparison With Existing Literature}

In our previous study of preferred risk communication modes, among patients with preexisting heart disease, most would be encouraged to take medication regardless of mode of risk communication, although they preferred graphic representation and relative risk to other forms of communication. ${ }^{4}$ The current study extends this work to patients across a much wider range of real cardiovascular risk, with a similar finding of overwhelming preference for relative risk. Hux et al also found that patients are more likely to take preventative medication when benefits were expressed in terms of relative risk ("34\% reduction in heart attacks") than in absolute risk difference ("1.4\% fewer people have heart attacks") or number needed to treat ("treat 71 persons for 5 years to prevent 1 heart attack"). ${ }^{7}$

A study that compared the likelihood of patients taking a hypothetical drug to prevent heart attacks expressed as number needed to treat (treat 13 people for 5 years to prevent 1 heart attack) with the therapy expressed in terms of postponing the heart attack (all patients who take the drug will live about 2 months longer), found number needed to treat was the most encouraging format. ${ }^{6}$ In this case, however, patients were comparing the possibility of not having a heart attack with a short prolongation of life; hence, it does not seem surprising that under these circumstances they would prefer the number needed to treat option.

A further study documented findings from focus groups of patients who were given their short-term CVD risk score to assess whether it assists in decisions to initiate various CVD reducing strategies. ${ }^{17}$ In discussion participants focused more on the relative or absolute risk reduction than on their level of CVD risk.

Māori and Pacific Islander populations are important within New Zealand. Pacific populations are an important minority in some other regions, including in the United States. That the ethnic and socioeconomic status explained relatively little variance in the sample suggests that our results may be generalizable to other populations.

\section{Implications for Future Research and Clinical Practice}

Irrespective of education, numeracy score, socioeconomic status, or actual CVD risk, patients showed strong preference for relative risk as a means of encouraging them to take preventive medication. Reducing absolute risk from $5 \%$ to $3 \%$, however, affords much less benefit than from $30 \%$ to $20 \%$ (the same relative risk reduction). Patients' decisions to participate in a screening program can be influenced by the way information is presented, ${ }^{18}$ and discussing benefits only in terms of relative risk may overly influence their decision making. ${ }^{19}$ We should not assume that patient choice necessarily indicates truly informed decision making, ${ }^{18}$ nor is it clear how to formally measure when a decision is 'right' or fully informed.

Given the commonplace observation that individual patients may make choices that do not match what a clinicians believes is the best for that individual, ${ }^{20}$ or a health funder has determined as best for the population, there arise unresolved ethical dilemmas. Because we cannot predict which mode of communication is preferred by individual patients, clinicians need to routinely use several modes and formats to communicate risk. In principle, clinicians should flexibly matching information to the needs of individuals. ${ }^{5}$ Patients, however, still may have difficulty understanding descriptions of treatment benefit regardless of presentation, or simply prefer clinical opinion. ${ }^{21}$ Widespread poor numeracy requires transparent risk communication such as absolute instead of relative risks and natural frequencies rather than conditional probabilities. ${ }^{9}$ Otherwise, our numbers and our words have the potential to manipulate patients. ${ }^{9}$

To read or post commentaries in response to this article, see it online at http://www.annfammed.org/cgi/content/full/9/2/121.

Key words: Risk assessment; risk management; decision making; family practice; cardiovascular diseases

Submitted March 15, 2010; submitted, revised, August 6, 2010; accepted August 20, 2010.

Funding support: This project was supported by a grant from the National Heart Foundation of New Zealand.

Some findings from this study have been presented at the Annual Scientific Conference of the Royal New Zealand College of General Practitioners, Wellington, New Zealand, September 9-12, 2009, and at the 37th Annual Meeting of the North American Primary Care Research Group, Montreal, Canada; November 15-19, 2009.

Acknowledgements: We wish to thank the general practitioners, practice nurses, and other staff who assisted in the study and especially to the participating patients. 


\section{References}

1. New Zealand Guidelines Group. New Zealand Cardiovascular Guidelines Handbook. A Summary Resource for Primary Care Practitioners. Wellington: New Zealand Guidelines Group; 2009.

2. Alaszewski A, Horlick-Jones T. How can doctors communicate information about risk more effectively? BMJ. 2003;327(7417):728-731.

3. Alaszewski A. A person-centred approach to communicating risk. PLoS Med. 2005;2(2):e41.

4. Goodyear-Smith F, Arroll B, Chan L, Jackson R, Wells S, Kenealy T. Patients prefer pictures to numbers to express cardiovascular benefit from treatment. Ann Fam Med. 2008;6(3):213-217.

5. Edwards A, Elwyn G, Covey J, Matthews E, Pill R. Presenting risk information-a review of the effects of "framing" and other manipulations on patient outcomes. J Health Commun. 2001;6(1):61-82.

6. Halvorsen PA, Selmer R, Kristiansen IS. Different ways to describe the benefits of risk-reducing treatments: a randomized trial. [Summary for patients in Ann Intern Med. 2007 Jun 19;146(12):150; PMID: 17577002]. Ann Intern Med. 2007;146(12):848-856.

7. Hux JE, Naylor CD. Communicating the benefits of chronic preventive therapy: does the format of efficacy data determine patients' acceptance of treatment? Med Decis Making. 1995;15(2):152-157.

8. Bobbio M, Demichelis B, Giustetto G. Completeness of reporting trial results: effect on physicians' willingness to prescribe. Lancet. 1994 14;343(8907):1209-1211.

9. Gigerenzer G, Gaissmaier W, Kurz-Milcke E, Schwartz LM, Woloshin S. Helping doctors and patients make sense of health statistics. Psych Sci Pub Int. 2007;8(2):53-96.

10. Alwan HA, William JB, Viswanathan BB, Paccaud FA, Bovet PAB. Perception of cardiovascular risk and comparison with actual cardiovascular risk. Eur J Cardio Prev Rehab. 2009;16(6):556-561.
11. Friedmann PD, Brett AS, Mayo-Smith MF. Differences in generalists' and cardiologists' perceptions of cardiovascular risk and the outcomes of preventive therapy in cardiovascular disease. Ann Intern Med. 1996;124(4):414-421.

12. Edwards A, Unigwe S, Elwyn G, Hood K. Effects of communicating individual risks in screening programmes: Cochrane systematic review. [see comment]. BMJ. 2003;327(7417):703-709.

13. Pignone M, Phillips C, Mulrow C. Use of lipid lowering drugs for primary prevention of coronary heart disease: meta-analysis of randomised trials. BMJ. 2000; 21;321(7267):983-986.

14. Jackson R. Guidelines on preventing cardiovascular disease in clinical practice. BMJ. 2000; 11;320(7236):659-661.

15. Schwartz LM, Woloshin S, Black WC, Welch HG. The role of numeracy in understanding the benefit of screening mammography. Ann Intern Med. 1997;127(11):966-972.

16. Crampton P, Salmond C, Kirkpatrick R. Degrees of Deprivation in New Zealand: An Atlas of Socioeconomic Difference. 2nd ed. Auckland: David Bateman Ltd; 2004

17. Sheridan SL, Behrend L, Vu MB, Meier A, Griffith JM, Pignone MP. Individuals' responses to global CHD risk: a focus group study. Patient Educ Couns. 2009;76(2):233-239.

18. Edwards A, Unigwe S, Elwyn G, Hood K. Effects of communicating individual risks in screening programmes: Cochrane systematic review. BMJ. 2003;327(7417):703-709.

19. Epstein RM, Alper BS, Quill TE. Communicating evidence for participatory decision making. JAMA. 2004;291(19):2359-2366.

20. Buetow S. Non attendance for health care: when rational beliefs collide. Sociol Rev. 2007;55(3):592-610.

21. Halvorsen PA, Selmer R, Kristiansen IS. Different ways to describe the benefits of risk-reducing treatments: a randomized trial. Ann Intern Med. 2007;146(12):848-856. 